Nicoletta Vallorani*

\title{
Faithful to the Wor(l)d. Visual Texts, Responsibility and the Issue of Translation
}

https://doi.org/10.1515/pol-2021-2014

Abstract: My work here focuses on translation and migration, with specific reference to the field of visual arts, exploiting the kind of approach suggested by Loredana Polezzi - and mostly applied to linguistic translation - in her "Translation and Migration". My contention is that, though apparently mimetic and universally understandable, images are culture-bound and they need being translated when crossing a border. The process of translation becomes more and more complex when the represented object/events/person is framed within a much-debated and politically overloaded issue. Focusing on a definite time (today) and a specific space (the Mediterranean Sea), I select some artistic projects by both Western and non-Western artists, pursuing a twofold objective. I want to show how the selected works raise the issue of responsibility and I want to reflect on the "language" they use to "translate" an untranslatable experience into an understandable message.

Keywords: migration, translation, visual arts, Mediterranean Sea

\section{The Wor(l)ds of Images}

Migration is probably the issue that is currently producing the highest number of texts - creative and scientific - authored by Westerners and non-Westerners, on both sides of the Atlantic, in the frantic attempt to give a manageable shape to an emergency that, in most cases and in variable percentages, results from a colonizing, imperialistic process ascribable to the Western powers themselves. In many occurrences, the texts produced are visual (films, documentaries, videos, photographic projects, performative and theatrical projects), and they circulate widely, apparently more freely than written texts, on the misleading assumption that a visual text does not need to be translated when crossing a border. When faced with these texts, the European and Western audience tends to have a mixed reaction

Article note: This article expands the work begun in the volume The Relocation of Culture, coauthored by Simona Bertacco and Nicoletta Vallorani, published by Bloomsbury in 2021.

*Corresponding author: Nicoletta Vallorani, Università degli Studi di Milano, Milan, Italy, E-mail: nicoletta.vallorani@unimi.it 
that is at the same time of familiarity and foreignness. The texts call for translation even when they are visual, but precisely because they are visual, they give the impression of being more understandable and therefore they often happen to be the most feasible tool for approaching complex issues. My analysis of some projects and artwork mostly produced by young artists, both Westerners and "foreigners" (for lack of a better definition), aims to show the ways in which translation relates in multiple ways to the effort to show, explain and take responsibility for the current emergency of migration, or to the sudden awareness of being unable to account for past, imperialist responsibilities in determining or opening the way for the tragedy occurring in many parts of the world.

I will focus on a specific time (today) and space (the Mediterranean Sea) so as to select comparable projects. And I will stick to the issue of responsibility relying on the connection that Loredana Polezzi identifies between migration, translation and political action, raising the issue of a biopolitics of language still to be articulated ${ }^{1}$ and very much missing in the case of visual texts. They connect more easily and immediately to the actual condition of the migrant as somebody who is obliged to move, often with no possibility of becoming an active agent in the process leading from one place/language/culture/religion/family to another, experiencing an act of physical translation that corresponds to the etymological meaning of the word. As Polezzi remarks, "transducere" means to take a passive subject from one place to another. ${ }^{2}$ In visual texts, the viewers can "see" the act of border crossing, and somehow experience by proxy what they observe in photos, films, videos and the like. In many cases, they are provided with full visual evidence of the restraints, dangers, violence, injustice, sorrow and loss implied in the journey of migration. But watching, even attentively, is not understanding, in the same way as filming or taking pictures does not necessarily amount to providing a fully aware testimony. As Westerners, when encountering migrants, we encounter "strangers". The foreignness we perceive is both linguistic and cultural. Language is more easily accounted for and translated than culture, though the two aspects are sides of the same coin.

Any culture (and its implied Weltanschauung) is normally represented through different codes, collectively agreed upon within the same community and over time. These codes are in progress, being -as Stuart Hall maintains - signifying practices. $^{3}$ As a consequence, translation is at stake not only as an operation concerning words, but as a (less visible) process regarding images: visual texts

1 Loredana Polezzi, 'Translation and Migration', Translation Studies, 2012, 347.

2 Polezzi, 349.

3 Stuart Hall and Open University, eds., Representation: Cultural Representations and Signifying Practices, Culture, Media, and Identities (London; Thousand Oaks, Calif: Sage in association with the Open University, 1997), 5. 
respond to less perceptible - but nonetheless existing - shared codes. When images are moved to a different context, when they cross borders, they need to undergo new paradigms of translation, a grammar that is yet to be invented.

This is the process I want to analyze here. More specifically, I want to work on "visual translation", meaning by that the way in which images, performances and videos conceived in a specific context are "translated" (understood and given meaning) into another. The process is very much built in analogy with linguistic translation, but it may prove more complex. We need an alphabet for this operation, there's no specific critical approach and we still suffer from the deeply rooted misunderstanding that still affects the reaction of the public to any representation by images. They are automatically and often unconsciously considered mimetic, whilst they are not. If it is true that "Seeing comes before words," it is also true that you decide what you want to look at and what selection of the visible world you want to depict when encoding a text. And, from the point of view of the addressee, you decode a text by exploiting a "code" and a "grammar" you are familiar with, and which may be different from the ones familiar to the author of the text. ${ }^{5}$

That is why the condition we (the Westerners) are dealing with requires the kind of "non-linear process of translation" that Loredana Polezzi mentions in her seminal article "Translation and Migration"6 and that is all the more necessary when approaching visual texts. By their very nature, they are complex because they normally combine different codes (words, but also colors, sounds, deictic elements etc.) in the same representation. Complexity is a problem, because it is never easily untangled, but also a resource, because it may be exploited so as to make complicated issues manageable and understandable. Finally, representation, when intended as such, is a political act, in the etymological sense of the words: it concerns the building, maintaining, protecting and reshaping of the community. It therefore naturally involves responsibility.

In this respect, the geography I focus on poses some additional problems. ${ }^{7}$ The Mediterranean Sea is a contested space, both symbolically and topographically. Despite Braudel's conviction of the essential unity of the cultures produced in this area, ${ }^{8}$ this unity appears, as Horden and Purcell state, a residual concept rooted in

4 John Berger, Ways of Seeing: Based on the BBC Television Series Directed by Michael Dibb, Reissued as part of the Penguin Design Series, Penguin on Design (London: British Broadcasting Corporation, 2008), 15.

5 Berger, 10-15.

6 Polezzi, "Translation and Migration," 350.

7 Simona Bertacco and Nicoletta Vallorani, The Relocation of Culture: Translations, Migrations, Borders. (S.1.: Bloomsbury, 2021), 69-72.

8 Fernand Braudel, The Mediterranean and the Mediterranean World in the Age of Philip II (Berkeley, Calif: University of California Press, 1995), vol. I. 
"The perpetuation of an ancient ideal of thalassochracy."9 The fabric of culture and its related politics have in fact become highly fragmented over time, revealing the fallacy of the idea that we belong to the same race merely because the so-called European civilizations arose along the borders of the same sea. Therefore, my research questions are: how do we, the Westerners, take responsibility for what is happening here and now in the Mediterranean Sea? How do we make this gigantic tragedy manageable? How do we relocate Caliban's rage within a geography that is European but also peri-African, overcoming the presupposition that "it is the idea of racial difference that makes both his alterity and his rage intelligible" ${ }^{10}$

Representation demands the act of acknowledging one's own responsibility. We are Westerners. There is no use in denying this. We are endowed with a Western gaze, producing certain kinds of representations that are culture bound. Such work as Jenny Erpenbeck's Gehen, ging, gegangen (2015), Anders Lustgarten's Lampedusa (2015) and even Kevin McElvaney's RefugeesCameras (2015) honestly try to go beyond the borders of Western cultures and Western gaze. ${ }^{11}$ I am interested in the way in which work analogous to these and produced by artists of different origins and nationalities try to represent migration in the closed basin of the Mediterranean Sea, exploiting the individual characteristics of their gaze but also relating to culturally familiar contents, that are reshaped and given new meaning in their creations.

\section{Ships and Boats}

A sea, any sea, simultaneously connects and separates. It can be crossed by ship, but shipwrecks are possible, in some cases inevitable, given the circumstances of the journey. In the most recent artistic representations of Mediterranean crossings, the ship is an overly represented object, marked by a profound ambiguity: it is a tool for reaching a safe haven but it may suddenly turn into a coffin. It is fragile and bound to sink when it is unsuitable for the open sea and/or overloaded. It may easily and fruitfully become a symbol of the current emergency in the Mediterranean Sea, while at the same time evoking Odysseus and his troublesome journey back home.

9 Peregrine Horden and Nicholas Purcell, The Corrupting Sea: A Study of Mediterranean History (Oxford, [U.K.]; Malden, Mass: Blackwell, 2000), 25.

10 Paul Gilroy, 'Lecture I. Suffering and Infrahumanity', Tanner Lectures on Human Values (Yale (USA): Yale University, 21 February 2014), 30.

11 All these works are closely investigated in chapters 3 and 4 of The Relocation of Culture. 
Sara Alavi, an Iranian artist born in Teheran, educated in Rome and Milan, and working in an international context, has devoted a long-standing project to the representation of the fragility of the ship. The first step, experientially related to a period she spent as a volunteer in a shelter for migrants in Milan, was the shaping of small boats in clay, painted in blue. Exposed to water, the boats gradually melted, leaving a puddle in their wake. The second step was "Entropy", an installation that combined the clay boats and the water drops slowly dissolving them with recorded voices reading testimonies that Alavi had collected when working in the shelter. In 2018, Alavi returned to the idea, producing a more complex representation for an exhibition at Villa Tittoni (Desio, Italy). Framed within the grand architecture of one of the most well preserved aristocratic villas in Brianza, Il mare fu ... started with a path of numbered envelopes containing letters, memories of the artist's volunteer work with asylum seekers. Following the envelopes, the visitors arrived in a large room patently full of small, fragile boats. Each of them was engraved with a number, meaning that each boat was coupled to an envelope and to a letter, and the three objects together told a story that was unique, sad and distinct from any other. Some boats were broken, so the journey of hope had not been completed. Some were bigger and some were smaller. Each of them, the artist suggests on her website, was in fact a face: sharply individual and well visible. ${ }^{12}$ Alavi returned to the same inspiration in a workshop/installation held during the Malta Festival in Poland, in 2020. She gathered 10 students to make the clay boats and 10 to participate in a storytelling workshop meant to produce imaginary tales of the people - Jewish and Polish workers, including children, imprisoned by the Nazis between 1940 and 1942 - who had built the artificial basin of Rusalka Lake. The tales were then recorded and mixed up with the artist's archive of refugees' tales. During the exhibition, the boats were displayed and drops of water fell onto them, slowly melting the clay, while recorded voices repeated the stories of both the refugees and the imprisoned workers, describing their physical and symbolic journey to the safety they craved. As the boats dissolved, the souls of the tellers were declared to acquire freedom, but their stories remained as a gift of memory. Step by step and through images, words and sculptures, Alavi seems to produce a kind of non-linear translation of the condition of the migrant, filtering an experience very hard to imagine through other more understandable references (her own work as a volunteer as well as the combination of refugees' tales and the stories of other prisoners held in the area of the lake in 1940 and then executed en masse). Moreover, using the clay boats as the key-object of the project, Alavi resemantizes the Mediterranean journey replacing the safe ship -

12 More details and images are available here: https://alavisara.com/it/806-2/ (last access May 2021). 
traditionally understood as such when at sea - with a perishable (and sometimes perished) boat and numbers with individual words. By doing so, she raises the issue of "Mediterranean responsibility for Mediterranean deaths" 13 as a picklock to open the room of understanding, an alphabet to translate the humanitarian tragedy taking place in the Mediterranean Sea. The dual function of a sea that connects and separates at the same time, according to the means and possibilities of the traveler, is given full evidence, in words, images and (perishable) shapes, leading the viewer to identify the full impact of the tragedy taking place in the Mediterranean Sea. This kind of position is well debated, from a critical and activist point of view, by Maurizio Albahari when he states that "[...] while transnational proximity and a complicated history bind the Mediterranean basin, the scholarly tenet of a 'Mediterranean' cultural unity has been exhaustively challenged (Herzfeld 2005) as orientalist and even as instrumental to colonialism."14

Isaac Julien's three-screen installation entitled Western Union Small Boats (2007) develops along the same line of thought. When the installation was produced, the policies to be followed by Europe on the issue of immigration were being shaped and very much the topic of the day. For an artist, it was actually impossible to ignore the issue. In creating his work, Julien chose to focus on landscapes more than people, objects represented through the poetic filter of a pictorial sensibility. The viewer, plunged in a dark room and surrounded by images, enters the stage where the endless tragedy of migration by sea is represented. Ships and boats appear mostly in the form of brightly colored wreckage side by side with a dancing body and against a blue sky. Blue is the sea where unknown bodies sink. Abandoned clothes and rags evoke a lost human presence. And the gaze of a person through gated doors looking onto the sea is revealing as to the fate of the migrants. ${ }^{15}$

The single-screen format of the same work challenges the very notion of storytelling proposing a multi-layered representation where the key to understanding resides in the emotional reactions to what is shown rather than in a precise and rational appraisal of what is narrated. Meaningfully enough, the work is entitled The Leopard, thus evoking the world-famous novel by Tomasi di Lampedusa Il gattopardo (1958) as well as its equally successful film adaptation (1963): both are set in the area that is suffering the impact of forced migrations maybe more than any other. ${ }^{16}$ This may be an effective way to approach the issue of understanding

13 Maurizio Albahari, 'After the Shipwreck: Mourning and Citizenship in the Mediterranean, Our Sea', Social Research 83, no. 2 (Summer 2016), 275-76.

14 Albahari, 276.

15 Details of the project are available here: https://www.isaacjulien.com/projects/western-unionsmall-boats/ (last access May 2021).

16 Maylis de Kerangal exploited the same reference in her A ce point de la nuit (2014), as analyzed in The Relocation of Culture (72). 
what is totally foreign (like the experience of forced migration). Gilroy writes that there is no understanding without compassion, which means suffering together. ${ }^{17}$ And suffering is emotional, not rational, and also pre-cultural and pre-linguistic, ${ }^{18}$ therefore more easily conveyed through codes other than language. Julien, a filmmaker and an installation artist based in London, is fully aware of the potential of visual arts, and manipulates the codes at his disposal so as to create a poetic and unique language.

Besides being a fully aware expressive choice, the almost organic relevance Julien gives to objects and fragments of landscape, tends to crop up in many artistic projects focusing on similar issues. ${ }^{19}$ It is in fact the starting point of Giacomo Sferlazzo's Verso Lampedusa, ${ }^{20}$ a work literally resulting from the act of gathering objects that had been accidentally left (around and) or lost by people on the run from war, famine, dictatorship and political persecution in general. Around 2005 and exploiting the wooden debris of multiple shipwrecks and two pages of the Quran, he composed a painting that is in fact a collage (bits of painted wood, pages of the Quran, oil on canvas) that transforms forgotten objects into reminders of a condition that we (the Westerners) contributed to create. Oggetti migranti (Migrant objects), in the section of his website entitled Discaricarte, consists of 23 similar works, also including the installation Contro l'identità (2013): ${ }^{21}$ a spiral drawn on the sand using the lost ID cards of the migrants: a document that is at the same time vital, universally known and often impossible to obtain for an asylum seeker or a refugee. Sferlazzo exploits the awareness of an all too familiar object to translate, through art and for an international public, the craving for a new home and the desperate search for a new identity. The message is effective because it is simple and direct. And because the materials it is made of tell a universal story of exile and loss.

In all his work, Sferlazzo takes a highly political stance, emphasizing the need for a kind of artistic activism that implies the awareness of one's own responsibility as a Westerner. On the website of Askavusa, the collective he contributed to

17 Paul Gilroy, Postcolonial Melancholia. (New York: Columbia U.P., 2006).

18 Peter Brooks, Body Work: Objects of Desire in Modern Narrative (Cambridge, Mass: Harvard University Press, 1993), 7.

19 The Italian photographer Mario Badagliacca chose the same kind of approach in his project Frammenti (2013-https://www.mariobadagliacca.com/frammenti_2013-r8112) (last access May 2021).

20 The project is available here: https://www.giacomosferlazzo.com/copia-di-arte. Verso Lampedusa corresponds to image 1 (last access May 2021).

21 The project is available here: https://www.giacomosferlazzo.com/copia-di-arte. Contro l'identità corresponds to image 15 (last access May 2021). 
creating, he clearly explains his reaction to finding the objects that he later decided to use in his paintings and installations:

Venire in contatto con quelle cose, fu per me l'apertura ad un nuovo alfabeto, un linguaggio muto e senza regole. Esperienza che avevo già vissuto, ma mai con questa potenza e con cosi tante implicazioni, ebbi l'impressione di avere a che fare con qualcosa di molto grande, come se mi fossi messo a tirare dei fili con cui erano collegate migliaia e migliaia di persone. ${ }^{22}$

Sferlazzo's art is in fact inseparable from his collaboration with the Askavusa Collective. Founded in 2009, the Collective has actively contributed to other visual projects through which the artist and activist has tried to create a new alphabet that might more easily represent on an international horizon the complex border struggles taking place in Lampedusa. ${ }^{23}$ Askavusa has become the hub and the aggregator of a number of events and demonstrations combining political activism and artistic practice and promotion. Porto $M$, probably their most important project, provides a clear idea of the kind of attitude they choose. As shown in the video Porto $M,{ }^{24}$ Francesca and Annalisa make it clear that they are creating new spaces for memory while making a conscious effort not to appropriate the objects belonging to the migrants by transforming them, as often happens, into artistic gadgets to be sold. ${ }^{25}$ What the activists do, in fact, is simple: they show respect. As Oberprantacher observes, in his very accurate and at the same time deeply empathic article "Of Other Spaces (of memory)", Porto $M$ seems to build an analogy between the fragility of the objects collected and the vulnerability of Lampedusa as a contested and threatened space, "located at the very margins of the European Union." 26 Within this troubled context, the museo diffuso proves "capable of bending hegemonic narratives about the recent history of migration by blending in residues of people who have disappeared after their passage to the European Union and by commemorating the probable stories of countless others who did not make it across. Or, as the collective Askavusa, which initiated Porto M, puts it on their rudimentary homepage:

22 See https://portommaremediterraneomigrazionimilitarizzazione.wordpress.com/storia/ (last access May 2021).

23 Sandro Mezzadra and Brett Neilson, Border as Method, or, the Multiplication of Labor (Durham: Duke University Press, 2013).

24 The video is available here: https://portommaremediterraneomigrazionimilitarizzazione. wordpress.com/ (last access May 2021).

25 Andreas Oberprantacher, "Of Other Spaces (of Memory)," Social Research 83, no. 2 (Summer 2016), 342-243.

26 Oberprantacher, 335. 


\begin{abstract}
We believe that it is important not to have any particular expectation, neither of the spectators, nor of the objects that are put on display. But then why put objects on display altogether, one could ask, why retrieve them, preserve them, and polish them? Precisely because we believe that these objects need to be displayed; they do not need to be studied, catalogued, restored, or "imprisoned," but instead displayed without adding anything else. To do this without any instructive information is not a neutral act, but a political choice ... We are simply searching for the road that has brought us into this dump (Askavusa 2014; translated by the author). ${ }^{27}$
\end{abstract}

What appears crystal-clear in the words of the Collective is the complete awareness that the Mediterranean Sea is an actual place and a crossroad for human trafficking, ONG rescues, military control and, only in some cases, trade and fishing. It is a grave, some say. And it requires some rites of mourning.

\title{
3 Learning How to Mourn
}

Sferlazzo's gallery of Oggetti migranti concludes with a tryptic: three black paintings entitled Lutto (mourning). Black is the Western color for mourning, though not universally understood as such. The fact that the objects used in the paintings are scarves also evokes the feminine act of covering one's head in the current, traditional attire required for a funeral. Again, Sferlazzo is using the objects he came across, the leftovers of several, repeated shipwrecks, to produce an artistic text that is meant to "translate" the death of a person whose body has never been found, whose identity is uncertain and whose family and relatives are probably unaware that they've lost a next of kin. In a shipwreck, names and belongings get mixed up, and differences are overcome by the frantic effort to survive, at any cost. The enormous numbers of the "ungrievable dead" - to borrow a definition from Butler's seminal study on Antigone ${ }^{28}$ - paving the Mediterranean seabed requires the acknowledgement of some responsibility and an effort to transform mere numbers into individual names and identities, to be commemorated as such.

Therefore, the issue raised here is, how do we, as Westerners, mourn such a gigantic tragedy? How do we take responsibility for those deaths? As in the classics, death rites are to be seen as relating both to the collective democratic body of the community and to the more intimate family circle. In other words, as in Sophocles's Antigone, the issue is at the same time political and private. ${ }^{29}$ In any

27 Oberprantacher, 335-36.

28 Judith Butler, Antigone's Claim: Kinship between Life and Death, The Wellek Library Lectures (New York: Columbia University Press, 2000).

29 Bonnie Honig, “Antigone's Lament, Creon's Gried: Mourning, Membership, and the Politics of Exception,” Political Theory 37, no. 1 (February 2009), 7. 
culture, the burial rite is politically important and privately relevant. Partly on these grounds, though within the framework of a more articulated discourse, the German Center for Political Beauty started a radical campaign entitled The Dead Are Coming (2015). It is by no means the first activist action undertaken by the Center. Founded in 2008 by the young political historian and activist Philipp Ruch, ZPS (Zentrum für politische Schönheit) is "an assault team that establishes moral beauty, political poetry and human greatness while aiming to preserve humanitarianism. The group's basic understanding is that the legacy of the Holocaust is rendered void by political apathy, the rejection of refugees and cowardice. It believes that Germany should not only learn from its History but also take action" 30 They engage in "operations" that are in fact provocative and revolutionary forms of art addressing more or less directly the institutional powers responsible for the political apathy that has betrayed the legacy of the Holocaust resulting in a loss of humanitarianism. In this respect, The Dead Are Coming hits home when raising the issue of European responsibility for the refugee crisis, particularly when Mare Nostrum, which started in 2013 in the wake of the major shipwreck that occurred on October 11, 2013, was replaced by Triton and supported by the European Agency Frontex. The latter was in fact leading military operations to protect European borders, and rescuing migrants was not a priority.

As Delano and Nienass write, "While this intervention brought the European border and its effects closer to the land-locked continental center, six months later the German artistic initiative Center for Political Beauty (ZPS) used the inverse strategy, moving crosses commemorating the victims of Eastern Germany's closed border regime ("Mauertote") from Berlin to European Union (EU) border regions, including Bulgaria and the Spanish enclave Melilla." ${ }^{31}$ Faced with the inability of politics to approach the emergency whilst staying human and prioritizing humanitarian issues, ZPS decided to show the kind of pietas due to any dead, from whatever origin, as an act of sympathy and humanity. In The Dead Are Coming, the heart of the operation, closely reported on the center's website, consisted in taking the dead migrants hastily buried in various locations in southern Europe and bringing their bodies right to the place they wanted to reach. Their burials were celebrated in various sites in Berlin, allowing different religious rites. The initiative was both poetic and political. It took the travelers, even beyond death, to their wished-for destination and it "gave words" to a definite political stance, translating the rejections of Fortress Europe into a subversive, constructive and comforting act. ${ }^{32}$ This act is universally understandable because it is grounded in

30 See https://politicalbeauty.com/index.html (last access May 2021).

31 Alexandra Delano Alonso and Benjiamin Nienass, "Introduction: Borders and the Politics of Mourning,” Social Research 83, no. 2 (summer 2016), xix.

32 (also criticized for being in bad faith and disrespectful for the dead) cfr. Art. New York Times. 
"sentiments about the equality of the living and their equal claims to honor in death" that go back to the times of ancient Greece and to Homer. ${ }^{33}$ Obviously, "The missing person or the migrant body is no longer a danger to government control but is reincorporated as a passive object-an individual with name, place of birth, and death-into the political system." ${ }^{34}$ At the same time, restoring individuality and identity to each exhumed body, ${ }^{35}$ the activists of the center try to provide the relatives of the dead with the most suitable tools to overcome the "ambiguous loss" mentioned by Pauline Boss, ${ }^{36}$ which actually makes it very hard to accept a death with no body. They help the European community to show in practice that they really want to take responsibility for what is happening in the Mediterranean Sea, thus not only symbolically but by taking action. Finally, it is also an act of healing and rebellion at the same time, contradictory and yet deeply human: the kind of gesture made familiar by Sophocles's Antigone.

Familiarity is the key to many projects exploiting the classics as a palimpsest for integration. In literature, Jenny Erpenbeck follows precisely this path in her Gehen, ging, gegangen, and so does Davide Enia's Appunti per un naufragio, ${ }^{37}$ at least in part. I will focus on a bigger, more ambitious and extremely successful performative project combining at least two related actions, which I find extremely relevant to my line of reasoning. I am referring to The Trojan Women Project. ${ }^{38}$ Started in 2013, basically as therapy through drama and addressing Syrian refugees in various areas, the project included a number of artistic practices allowing the participants, mostly asylum seekers and women, to make their voices heard through the acting and re-enacting of their mournful fate within the structural frame of a classic Greek tragedy. Euripides's Trojan Women (415 a.C.) was in fact adapted by Mariem Omari (a professional), together with Alaa Saloum and Sanaa Al Froukh (two newly arrived Syrian women). The final script placed notes, reflections and writings on refugee seekers side by side with lines from the original text. Victoria Beesley directed both the therapeutic workshops at Glasgow's

33 Honig, "Antigone's Lament, Creon's Gried: Mourning, Membership, and the Politics of Exception," 14.

34 Jenny Edkins, "Missing Migrants and the Politics of Naming: Names Without Bodies, Bodies Without Names," Social Research 83, no. 2 (Summer 2016), 378.

35 As Edkins notes, "The operation is made complex by the understandable resistance of the families and relatives to collaborate: The family may not wish to risk their relative's safety by alerting the authorities to their presence, or may well be unaware that the migrant-who is in any case no longer where they are supposed to be-is missing" (368).

36 Pauline Boss, Ambiguous Loss: Learning to Live with Unresolved Grief, 1. paperback ed (Cambridge, Mass.: Harvard Univ. Press, 2000).

37 Bertacco and Vallorani, The Relocation of Culture, 80-81.

38 Details of the project are available here: https://www.trojanwomenproject.org/ (last access May 2021). 
Platform Theatre and the play, which was then taken on tour both in Scotland and in England.

Again, the artistic experience that was gradually implemented in this case amounts to a kind of "non-linear translation" 39 that exploits a hybrid alphabet. A Greek tragedy that is a scream against war proved particularly suitable to reencode the horrors of the Syrian wars and massacres and the gigantic tragedy of loss and exile. Basically, the experience aimed to help the women overcome their sadness, isolation, trauma and radical loss. Over time, it produced a text that was able to give a very precise idea of what it meant to be pushed out of your own home and look for safety in a place where you are mostly unwanted.

Queens of Syria (Yasmin Fedda, 2014), the second artistic experience I am interested in, arose out of the same crucible. ${ }^{40}$ The documentary film is a spin-off of the play directed by Zoe Lafferty (2013) and adapted, again from Euripides. In this adaptation, the cast is deliberately and entirely formed by women, who are Syrian refugees. As in The Trojan Women, the narrative combines testimonies and excerpts from the Greek tragedy, creating a composite, mesmerizing text built on a hybrid alphabet, linguistically blended and powerfully expressive. Against the backdrop of minimalist scenography, the image of the women on stage, wearing their traditional clothes and hijabs, and standing proudly as they recite together or one by one the words of their exile, the intensity of their voices and expressions, the courage they show, make the film unforgettable.

The 13 protagonists of the film were ordinary women, they did not have any acting background and for the most part they came from very different family and professional backgrounds. They were in charge of telling the story of 50 female refugees from Syria, gathering in a refugee camp in Jordan in the Fall of 2013. They familiarized themselves with Euripides's tragedy identifying analogies between their own fate and that of the women in the Greek tragedy. They recognized each other while trying to heal their current trauma by impersonating the trauma of characters belonging to the ancient Greek world.

As I participated in the play I asked myself, what is the benefit out of this, what can this play do? Soon after, I understood that people in the West, unlike the East, they adore theatre, they respect and appreciate it. It influences them. Then the play gave me the space to talk to these people, in the language they understand too.

Performing Euripides was their therapy for overcoming trauma, but the therapy went beyond the intentions of the therapist when the women realized that their

39 Polezzi, “Translation and Migration,” 350.

40 Details of the project are available here: https://www.trojanwomenproject.org/queens-ofsyria-film. 
tragedy was perfectly reflected in the plight of the Trojan women. It was both revealing, in showing the inability of men to change, and comforting in demonstrating the possibility for the women, to struggle for a better life. The multiple reverberations of voices produced a unique performative effect and also showed that communication is sometimes made possible by the universal pattern underlying experiences such as slavery, violence, rape and exile, particularly when the victims are women. They share the fact of being at the same time vulnerable and stubborn in their determination to survive and to keep memory of the disasters of war.

\section{Where do We Go from Here?}

This reflection is by no means concluded. It is certainly true that translation is also relevant to visual texts in various and complex ways and exploits an alphabet that is still in the making, as it is true that this alphabet reveals complexities when the issues at stake concern highly debated matters, as happens for the refugee crisis in the Mediterranean Sea. Exploiting familiar images and texts, reshaping them and translating their contents into the needs of the current contingencies may be an effective bridge towards understanding.

It is double-sided of course: when recurring to familiar tropes, the artists run the risk of their own interpretation and epistemology overlapping with something that they do not really know, thus appropriating an experience that is not theirs. But at the same time - and this is what I think is currently happening, particularly in the visual and performative arts - the artists working in these fields, both Westerners and not, are moving towards the creation of a brand-new alphabet, that may eventually prove more effective than the traditional one. It will necessarily be hybridized and it will involve culture as a circuit marked by the fruitful interplay of different influences in which no culture has priority over the others by definition. I think that, maybe paradoxically, this process of non-hierarchical hybridization is coming closer in visual codes than in verbal language. Progressively, visual projects, performative actions, films and documentaries - particularly in the field of activism and in independent cinema - are already creating an international jargon that seems more independent from the Western obsession of being more ancient, more civilized, more everything.

There is only one way to get around this impairing belief, and it resides in the practice of respect. As artists, particularly if Westerners, we may exploit what is familiar provided we keep well in mind that something - what Benjamin marks as impossible to translate in language - will be left out, and needs to be respected and accepted as foreign, therefore different, therefore useful and revitalizing. 


\section{Bionote}

\section{Nicoletta Vallorani}

Università degli Studi di Milano, Milan, Italy

nicoletta.vallorani@unimi.it

Nicoletta Vallorani is Professor of English Literature and Cultural Studies at the University of Milan. Her lines of research combine the fields of visual studies and postcolonial studies, with references to film studies. She published on migration in the Mediterranean Sea (Nessun Kurtz. Cuore di tenebra e le parole dell'Occidente, 2017; Forms of Loss. Dead Bodies and Other Objects, 2018), the intersections between crime fiction and migration studies (Postcolonial Crime, 2014), and the literary representations of the urban margins (Millennium London. Of Other Spaces and the Metropolis, 2012). She contributed to the Routledge Companion of Crime fiction ("Crime Fiction and the Future" - 2020). She co-authored (with Simona Bertacco) the volume The Relocation of Culture (Bloomsbury 2021), prefaced by Homi K. Bhabha. 